\title{
SWOT-based Analysis of Development Strategy of Shandong Accounting Firms
}

\author{
Guili Xu \\ Shandong Yingcai University, Ji'nan, 250100, China
}

Keywords: Accounting industry. Accountant. Firm. SWOT analysis method

\begin{abstract}
Since China joined WTO, Chinese economy has developed continuously. Generally speaking, it is both an opportunity and a challenge. For accounting firms in China, they like sailing against the current in actual economic condition under the general environment. This paper will analyze and summarize prospect and development strategies of local accounting industry in Shandong from four perspectives of SWOT.
\end{abstract}

\section{Introduction}

As early as 1980s, American managerialist Weihrich put forward a method to analyze current situations and future improvement of enterprises and even any industry, called SWOT analysis method. SWOT analysis method involves four aspects: Strengths, Weaknesses, Opportunities and Threats. In an industry, if some enterprises do not clearly know their development direction and future roads, or hesitate, they can firstly use SWOT analysis method to analyze their strengths, weaknesses and potential threats and then formulate a long-term strategy plan according to development opportunities. We take accounting firms in China as the object of study and utilize SWOT analysis method to analyze the development of accounting firms in Shandong Province.

\section{Strategic analysis of strengths}

Strength as an important factor of SWOT analysis methods is mainly used to analyze the winning factors brought to accounting forms during benign competition with the same industry. These winning factors include excellent corporate reputation, good first impression, connotative core spirit, efficient professional level and low cost. We firstly analyze advantages of China and Shandong Province.

\section{Overall advantage in China}

Since China joined WTO, each local government has taken active part in various commercial activities of WTO.

This gives more economic analysis opportunities for Chinese numerous accounting industries. Besides, audit and qualification authentication of accountant system by the government becomes increasingly strict. Although accountant examination in some regions of China is too strict, the strictness degree for accountant qualification is on the rise. This improves overall professional quality of accounting industry.

The cost of accounting industry in China is generally low.

Firstly, Chinese accounting firms fail to form large operation scale. Most accounting firms are dispersive small companies. In some regions, an office building or a commercial residential house can become the office of accountants. Low office cost decides that their charging level is lower than that of international accounting firms. In particular, for many small and medium-sized enterprises in China, it is a good selection condition.

China strictly protects accounting industry.

For invasion of foreign economy, China's economic policy is based on joint development and prosperity of each industry. There is also a deeper-level advantage, i.e. generation and formation of cultural barrier. There are many cultural differences among different countries. Oriental and western ideology has a wide gap. So, even if some western developed countries have advanced accounting 
technique and more convenient auditing equipment, it is hard to span the wide gap among countries, let alone accounting cost will also rise. In addition, in national economic system, the combination of collectivism and market economy can promote common progress of each industry and meanwhile effectively resist penetration of foreign capital.

\section{Local strengths of Shandong Province}

\section{Economical and practical audit projects}

For China, as a coastal province, Shandong Province owns good economic development. Besides, it is easier to contact foreign advanced auditing means. The learning and absorption abilities of Shandong Province are also strong. But compared with other developed regions such as Beijing, Shanghai, Guangzhou and Shenzhen, the auditing cost of accounting firms in Shandong is much cheaper. For many Chinese small enterprises which cannot afford foreign high-end accountants, they have more choices.

\section{The quantity of customers has formed a group}

Native people in Shandong are forthright, which will also influences enterprise customers cooperating with accounting firms. The working mood can be infected. Besides, the publicity of the culture of Qi and Lu has deeply influenced cultural environment of Shandong. So, the enterprise customers handling accounting business and auditing work feel very warm. Good service attitude and enthusiastic working manner are appreciated. All these deepen good feeling of customers for accounting firms in Shandong.

\section{Strategic analysis of weaknesses}

Relative to strengths, weakness is also a very important constituent part of SWOT analysis method. Its contents include: lack of advanced technology, unscientific operation method, chaotic management system, no core spirit and unclear working standard. These weaknesses need correction and rectification. Only when we firstly recognize our gap with others can we catch up with them. So, we should have the correct attitude to cognize misunderstanding firstly. Weaknesses of accounting firms are generally related to the scale, facilities and technical level of personnel of the accounting firm.

\section{Overall weaknesses in China}

\section{Equipment level is poor and is not systematical enough.}

Compared with foreign professional accounting firms, the scale of Chinese accounting firms is too small. Chinese accounting firms start late with poor foundation. Foreign countries had set up a set of accounting management system in the period of rapid development of capitalism the early period of last century. In current developed countries, there are numerous accountants. Besides, they are high-end technical personnel. For accounting industry, these years is the golden development period. Moreover, accounting industry has shaped. But compared with foreign countries, there is still a large gap.

\section{The business types of accounting firms are few.}

Due to enterprise development in China, financial statement audit becomes a major item of accounting firms. Some accounting firms only depend on financial statements to maintain operation. This may easily lead to sluggish. Meanwhile, vast accounting firms make no attempt to make progress and only focus on this single business, thus leading to auditing service prevailing. Once a business prevails, accounting firms can only depend on this business to make profits. This causes other business departments have no development space and impetus.

\section{Local strengths of Shandong Province}

\section{Professional accounting personnel turnover is serious.}

Since Shandong is a coastal province, it is convenient to accept construction of many transnational enterprises. In the face of personnel recruitment by excellent transnational enterprises, many excellent accountants leave local accounting firms and take office in transnational enterprises. Although these belong to individual dream or pursuit, after getting high income, those excrement personnel may not come back and work for overseas-funded enterprises for a long time. Thus, local 
excellent personnel will change jobs. The cultivation cost cannot be recovered, and the benefit is gained by other accounting firms in other places.

\section{There is no large-scale brand.}

Accounting firms in Shandong are scattered in various places, without formation of scale effect. During mutual competitions, wrongful economic behaviors result in internal loss. If such non-benign competitions go on, accounting firms in Shandong Province will sag collectively and loss at both sides after mutual fighting. They cannot gain effective development and joint progress opportunity.

\section{Strategic analysis of opportunities}

Generally, opportunities are classified into an external cause in SWOT analysis method, for the emergence of opportunities is generally under objective environment.

\section{Overall opportunities in China}

After China officially enters WTO, there will be a large number of enterprises entering the market. For the accounting industry, these are rich and valuable customer resources. It is required to seize the opportunities under such general environment and cultivate customer group base belong to China. There may be foreign customers. Developing countries in each country of the third world represented by various countries in Southeast Asia may enter Chinese market for accounting business.

Entering world market will increase the quantity and types of accounting business. In the integrative economic tide, computing methods and advanced equipment used by excellent accountants in various countries in the world can be introduced in China. These computing methods and advanced equipment will become important ladders for Chinese accounting firms walking to high end and profession.

National government announced the decision about completely opening accounting market to the public in 2006. Favorable policies and treatment will greatly stimulate the number of accounting personnel. The quantity and scale of accounting firms will also increase. In the future, the proportion of the auditing service of accounting firms will reduce. Meanwhile, according to the new standard on accounting industry, it can be seen that auditing service standard will become higher, which can stimulate each firm to develop and innovate for other services.

\section{Strategic analysis of threats}

Threat as the last content of SWOT analysis is equally important. It and the opportunity emerge relatively. They have dialectical and uniform relationship. Once opportunities appear, threats will also follow. So, we should clarify the thought and see clearly what the opportunities bring to us and then judge the corresponding threats.

\section{Overall threats of accounting industry in China}

Insufficient cognition of accounting standards newly issued may lead to the decrease in the work efficiency of large quantities of accounting personnel. This is the policy and guideline formulated as the opportunity emerges. The policy and guideline are also potential threats. The beneficial places for us are called opportunities; on the contrary, the adverse places are called threats.

Favorable policies in accounting industry may make a large batch of people to be engaged in accounting work. The quality of accounting firms may be uneven. Just as stated above, new policies encourage prosperous development of accounting industry. As a result, a large number of accounting personnel join accounting firms. The opportunity is that new blood will be injected in accounting industry. Then, corresponding threat appear immediately. Once competitions become fierce, survival of the fittest is inevitable. Numerous accounting personnel will become vigilant.

New accounting standards add difficulties. This may influence lead to maladjustment of auditing personnel. The possibility of mistakes and omission will increase. This is the burden caused while professional accomplishment of accounting personnel increases. Maybe many cannot adapt new standards and then quit from the accounting industry. 


\section{Future development of accounting firms}

\section{Analysis conclusions}

On the whole, the overall direction of accounting firms has been clear, i.e. integrate to large-scale, integral and cooperative collective accounting firms. Accounting firms should carry out cooperative development through governmental regulation and control and firms reaching a common view. It is required to gradually replace previous scattered independent office with large-scale district management. Meanwhile, corresponding plans for new standards should be increased to deal with every-changing accounting work. Moreover, accounting firms should enhance accounting service expansion ability and cannot be limited to audit work. Novel, convenient and practical accounting work should be launched. This is also one method to increase the vigor of accounting firms.

\section{Strategic guidelines}

To solicit high-quality accounting personnel. National policies will make the number if accounting personnel increase. Among the new batch of accounting personnel, each accounting firm should carefully check their qualification during recruitment, then test their professional accomplishment and accounting abilities and assign work to them according to their features.

To implement enterprise management for merged accounting firms. After each accounting firm is merged, local differences and working habits will lead to many differences. Enterprise management can uniformly rectify each accounting firm, standardize accounting profession system and make the cooperative accounting firms become a tram for the sake of uniform management.

To expand international accounting items. International economic market is a wider stage, although there is certain competition pressure and capital invasion risk, the competitions without risk will have no corresponding high return. In the aspect foreign services, exchange and cooperation activities with other accounting firm in foreign developed countries can be carried out frequently, which contributes to increasing international information and learning and absorbing foreign advanced accounting experience.

\section{Conclusions}

For accounting firms, after they are merged, management convenience and calculation efficiency can improve. More importantly, brand awareness can be established for accounting firms in China in the future. Once we have brand awareness, enthusiasm of accounting personnel will boost. What's more, after brand awareness is established, the firms will really create accounting services belonging to their own brand and make them strong and larger. This is a long-term and great objective for accounting firms in China.

\section{Acknowledgments}

This paper is a planned project for social sciences in Shandong: On development status, problems and countermeasures of certified public accountant industry in Shandong - SWOT-based strategic analysis, No.: 12CKJZ16

\section{References}

[1] Sun Xiaohui, SWOT analysis of Chinese native accounting firms [J]. Friends of Accounting, 2012 (11)

[2] Zhu Limin, SWOT analysis of competitions of Chinese accounting firms and strategic choice [J]. Communication of Finance and Accounting, 2009 (25)

[3] Wang Chaomin, Thoughts on professional operation of accounting firm industry [J]. Modern Marketing (academics), 2010 (07) 
[4] Cai Lingking, Development strategy of Chinese accounting firms under open horizon SWOT-based analysis [J]. Friends of Accounting, 2010 (11)

[5] Hu Changcheng, Analysis of competition strategy of Chinese accounting firms [J]. Market Modernization, 2009 (11) 